\title{
Entre lo ritual y lo comercial. Reflexiones etnográficas sobre las prácticas religiosas del Movimiento Misionero Mundial en Lima, Perú
}

Recibido: 16/08/2018

Aprobado: 29/10/2018

\author{
JAIR ROLLERI \\ Universidad Nacional Mayor de San Marcos \\ Universidad Peruana de Ciencias Aplicadas \\ castel.rolleri@gmail.com
}

\section{RESUMEN}

El presente artículo propone una discusión etnográfica en torno a los rituales económicos en el pentecostalismo limeño y, particularmente, en el caso de la Iglesia Cristiana Pentecostés "Movimiento Misionero Mundial". Para ello, trazamos un recorrido teórico sobre los estudios que, desde la antropología y la sociología de la religión, se han desarrollado respecto de la ritualidad, el fenómeno protestante y su presencia en el Perú. En ese sentido, retomamos los trabajos de Turner, Rappaport, Berger, Luckmann, Marzal y Bastian. Para comprender la ritualidad del Movimiento, se desarrolló un estudio etnográfico de siete meses en el templo central del Presbiterio N.$^{\circ} 7$ del Movimiento Misionero Mundial, ubicado en Pueblo Libre, Lima. Como principal resultado de esta investigación, encontramos que las prácticas religiosas de esta iglesia evidencian una hibridación entre lo ritual y lo corporativo, es decir, entre el comportamiento movido por la fe y la estrategia movida por la lógica empresarial que, a su vez, estructura la vida social de la congregación.

Palabras clave: Religión, pentecostalismo, ritualidad, Movimiento Misionero Mundial.

\section{Between the ritual and the commercial. Ethnographic reflections about the religious practices of the Worldwide Missionary Movement in Lima, Peru}

\begin{abstract}
This article proposes an ethnographic discussion about economic rituals in Lima Pentecostalism and, particularly, in the case of the Christian Pentecost Church "Worldwide Missionary Movement". To do this, draw a theoretical course on studies that, from anthropology and sociology of religion, have been developed with respect to the rituality, the Protestant phenomenon and its presence in Peru. In that sense, we return to the works of Turner, Rappaport, Berger, Luckmann, Marzal and Bastian. To understand the rituality of the Movement, an ethnographic study of seven months was developed in the central temple of the Presbytery N..$^{\circ} 7$ of the Worldwide Missionary Movement, located in Pueblo Libre, Lima. As a main result of this research, we found that the religious practices of this Church shows a hybridization between the ritual and the corporate, that is, between the behavior motivated by faith and the strategy for the business logic that, in turn, structure the social life of this congregation.
\end{abstract}

Keywords: Religion, Pentecostalism, rituality, Worldwide Missionary Movement. 


\section{Introducción. La religión en el Perú y los desafíos de su abordaje}

Caracterizar el panorama religioso peruano representa, como afirmaba Marzal (2000), un desafío en términos de categorización y clasificación. Pese a ello, sí es posible considerar algunos aspectos generales sobre la investigación social en torno a las expresiones religiosas locales. En principio, el paradigma de la secularización, al menos como era entendido por Berger (1972) o Luckmann (1973), no terminó de consolidarse en el país, a diferencia de lo sucedido en otras regiones como Europa. Así, para el caso nacional, la idea de que la modernización de las ciudades y los Estados traería consigo un desencantamiento de las religiones fue desplazada por una proliferación mayor de iglesias. Es decir, el abandono nunca se produjo y, en su lugar, se desarrolló un proceso de redistribución continua de fieles, movido por las migraciones eclesiales, la aparición de credos nuevos y la escisión de algunos ya existentes. En términos estadísticos, si consideramos los últimos resultados censales (INEI, 2007), ${ }^{1}$ solo un 3.5\% del país se reconocía como "no creyente". Si bien algunos estudios como el de CPI (2014) muestran una expansión no religiosa hacia un 5.9\% y otros como el de la Pontificia Universidad Católica de Perú (PUCP, 2017) evidencian un $6.1 \%$ de personas "no creyentes" y $4.7 \%$ de "indiferentes" a la religión, ello no niega, al menos hasta la actualidad, que la metáfora de Marzal (2002), que concebía al Perú como una "tierra encantada", continúe siendo válida.

Un segundo aspecto que debe considerarse para la comprensión del panorama religioso peruano es la orientación de las migraciones confesionales. En ese sentido, si bien Marzal $(2002,2000,1988)$ no veía como necesariamente cercana la idea de una explosión protestante en el Perú, en la actualidad es válido afirmar que los movimientos evangélicos, en efecto, han crecido significativamente. De acuerdo con los resultados censales aludidos (INEI, 2007), la población evangélica era de un 12\% del total. CPI (2014), por su parte, la sitúa por encima del 15\%. La PUCP (2017), en un estudio más reciente, describe que un $13.5 \%$ de la población es evangélica. Pese a que dicho incremento aún no amenaza al catolicismo imperante, sí constituye un indicador de la movilidad confesional que caracteriza al panorama religioso en el país. Al

1 A la fecha de presentación de este artículo, los resultados sobre población religiosa del censo 2017 recién estaban siendo publicados por el INEI. Debido a ello, las cifras del censo 2007, pese a tener más de una década de desfase, constituyen todavía la versión oficial sobre la profesión religiosa en el Perú. No obstante, ello no niega la tesis de que, en lugar de un desencantamiento, exista actualmente una continua diversificación y movilidad confesional. Así, la secularización fue desplazada por el pluralismo. 
respecto, ya Bastian (1997, p. 206) había señalado que, más allá de la pérdida de fieles, el mayor impacto del crecimiento protestante era la "pentecostalización del catolicismo". En ese sentido, además de plural, el universo confesional peruano es dinámico y acaso híbrido.

Un tercer rasgo que define al mundo creyente en el Perú es su abigarramiento. Si consideramos la información estadística como criterio, salta a la vista que las alternativas de profesión religiosa son generalmente las mismas: católico, evangélico, otras religiones y no creyente. Sin embargo, en la práctica, el escenario es mucho más complejo, pues, según Marzal (2000), el uso de categorías es uno de los grandes problemas del estudio social de las religiones. Por citar algunos ejemplos, el rótulo de "evangélico" no necesariamente esclarece la filiación de metodistas, bautistas, adventistas, pentecostales, entre otros, que muchas veces no se consideran como hermanos entre sí. Por otro lado, es más frecuente la adscripción de los denominados "evangélicos" a la categoría "cristiano", que no se incluye en los cuestionarios y resulta todavía más ambigua, pues viabiliza la posibilidad de que un número significativo de fieles opte por identificarse bajo el rótulo de "otros". Finalmente, como se evidencia en el estudio de la PUCP (2017), el marcado por una confesión religiosa en un censo o encuesta no garantiza en lo absoluto la profesión real por esta. A manera de ilustración, de las personas consideradas "creyentes", más del $80 \%$ se identifica como "algo religiosa" o "poco religiosa".

Otro rasgo relevante para la comprensión del Perú religioso es su hibridismo. Lo híbrido, en términos antropológicos, se entiende, de acuerdo con García Canclini (2001), como el resultado de las adaptaciones que experimentan las manifestaciones tradicionales o populares ante fenómenos como la modernización. En ese sentido, si bien el Perú no se secularizó del todo, el impacto de esta tendencia mundial en el alejamiento de la religión erosionó, en cierta medida, las barreras entre las congregaciones. Si bien existen grandes gremios religiosos no católicos en el país como el Concilio Nacional Evangélico (CONEP) o la Unión de Iglesias Cristianas Evangélicas (UNICEP), ello no necesariamente altera la existencia de vínculos entre confesiones nominalmente distintas y tensiones entre congregaciones aparentemente unidas. Asimismo, tampoco suprime las mutaciones que, debido a factores no necesariamente religiosos, explican el dinamismo de las propias confesiones. Así como en la actualidad resultaría disparatado sostener la idea de culturas puras, la creencia en iglesias puras se asume como indefendible. Además del vínculo entre protestantismo y participación política, desarrolla- 
do por Gutiérrez (2017), difícilmente otro factor cohesionaría la pluralidad confesional en el país.

Finalmente, un último elemento a considerar para el análisis de la religión en el Perú es su relación con el mercado. Tal como señala Luckmann (1973, p. 109), el sujeto creyente no desaparece en la modernidad. Al contrario, las iglesias deben coexistir con la "mentalidad de consumidor" que adoptan los fieles. Ello se aprecia claramente en el país, sobre todo dentro de lo que Marzal (1988) llamaba "complejo mundo evangélico". La coexistencia de fines económicos, políticos y religiosos en las congregaciones, la irrupción de la lógica de mercado en todas las instituciones y la movilidad propia de un sujeto, no necesariamente moderno, pero sí enfrentado a la modernidad, generan un desafío mayor en las iglesias. La profesión de fe se asocia a un consumo religioso, lo que impulsa a los credos a adaptar sus mensajes, emplear medios masivos de comunicación y, como afirmaría Beck (2003), personalizar su oferta religiosa para adecuarse a un feligrés-consumidor.

En ese escenario plural, dinámico, abigarrado, híbrido y hasta cierto punto mercantilizado, no resulta extraña la existencia de iglesias que, sin abandonar sus propósitos ante todo religiosos, funcionan a la manera de un gran conglomerado empresarial. Ese puede ser el caso del Movimiento Misionero Mundial, congregación de origen portorriqueño, fundada en la década de 1950 y presente en el Perú desde la década de 1980. Una iglesia significativa de lo que Bastian (1994) denominaba "pentecostalismos latinoamericanos", con presencia en setenta y un países del mundo, poseedora de unos dos mil templos en el país y una cadena de estaciones de radio, televisión, medios impresos, plataformas web y aplicaciones para celulares de nombre Bethel Comunicaciones. Pero, prioritariamente, una agrupación religiosa y movida, por tanto, por fines asociados más a lo divino que a lo material.

No obstante, constituye una preocupación valida el interés por el funcionamiento económico de esta portentosa congregación. Una observación minuciosa de sus prácticas cotidianas evidencia que las actividades económicas del Movimiento son también religiosas, y viceversa. Por ello, el objetivo central de este trabajo reside en analizar cómo se funden lo corporativo y lo clerical en la ritualidad de esta iglesia. Con este fin, nuestra discusión se basa en un trabajo etnográfico de siete meses realizado en el templo central de Pueblo Libre, en Lima. Si bien no constituye la sede principal de la congregación, debido al funcionamiento corporativo de esta y a la similitud cultual en todos sus templos en la capital, resulta una experiencia cualitativamente significa- 
tiva para la comprensión del Movimiento. ¿Cómo a partir de la ritualidad se puede comprender el funcionamiento de la congregación y la expansión de la misma? Es una de las preguntas que el presente estudio se propone abordar.

\section{Aspectos teóricos: religión, ritualidad y organización social}

Desde los estudios clásicos de Durkheim (1968) y Weber (1978), resulta casi un dogma para las ciencias sociales entender a la religión desde una dimensión conceptual y otra conductual. En esa lógica, la religión es un "sistema solidario de creencias y prácticas que unen a una comunidad llamada iglesia con las cosas sagradas" (Durkheim, 1968, p. 49). Es decir, se puede comprender como una reciprocidad entre un conjunto de saberes en torno a lo sagrado que justifican una serie de comportamientos establecidos - o rituales - y, a la vez, los requieren para perpetuarse. Es en esa relación dinámica entre creencia y ritual que una comunidad, al menos para Durkheim (1968), se construye o cohesiona a partir de lo religioso. De ello se desprende que deba considerársele como un sistema, ante todo, socializador.

No obstante, la religión no es solo comunidad, creencia y ritual. Es, cuanto menos, un sistema de instituciones y jerarquías, o, en palabras de Weber (1978, p. 19), una forma de racionalidad social que vincula una concepción coherente del mundo a la ética económica de un estrato social determinado. Así, antes que un sistema complejo de elucubraciones teóricas, una religión articula una concepción racionalizada de la realidad con el sistema de normas de un sector particular de la sociedad. Dicho de otro modo, la religión, al menos en términos de Weber, es práctica antes que teórica y terrenal antes que divina. Las creencias y valores sagrados son una alternativa de respuesta a problemas y necesidades terrenales, y, por tanto, impulsan a los grupos sociales hacia un "comportamiento éticamente condicionado" (Weber, 1978, p. 13) que organiza la vida económica y acaso política de las personas en cuanto les ofrece "la teodicea de su buena suerte" (Weber, 1978, p. 11).

A partir de ello, podría considerarse a la religión como un sistema eficaz en cuanto socializa y mueve a la acción a los individuos en colectividad. Sin embargo, para hablar en términos de Luckmann (1973), esta eficacia de la religión solo es posible si el sistema adquiere condiciones de plausibilidad, es decir, si efectivamente los sujetos se adhieren al conjunto de creencias, a la práctica continua de rituales o a los valores éticos racionalizados. En esa 
lógica, conviene recurrir a Geertz (1988), para quien la religión no solo cohesiona, sino permite significar o justificar las vicisitudes de la vida individual. De acuerdo con Geertz (1988), el sistema religioso no solo ofrece modelos de sociedad sino modelos para la acción que justifican no solo el sistema de creencias, sino el rol del sujeto en la estructura social. De esta forma, al significar la individualidad, es posible que una persona, en efecto, mueva no solo su conducta sino su interioridad a un sistema religioso determinado.

Es así que conviene entender al fenómeno religioso, siguiendo a Marzal (2002), a partir de cinco dimensiones claramente distinguibles: creencia, ritual, organización social, ética y —aquí reside el gran aporte del autor a la definición- sentimientos religiosos. En ese sentido, un intento de comprensión, ya sea de una variante religiosa particular, de un panorama religioso nacional o, inclusive, de una iglesia específica, debe, para Marzal (2002), considerar estas cinco dimensiones de estudio y sus distintas formas de articulación. Para el caso del presente análisis, el elemento que se abordará es el ritual, es decir, la práctica religiosamente condicionada por la creencia y los valores de una congregación. Cabe precisar que se toma el estudio de la ritualidad porque, para citar a Turner (1988), los rituales constituyen una forma de ingresar a la estructura y la vida social de una colectividad. En otras palabras, analizar los rituales de un grupo religioso constituye una forma efectiva de comprender las otras dimensiones de dicho grupo, es decir, su sistema de creencias, formas de organización, patrones éticos y sentimientos individuales.

Ahora bien, si en lo metodológico el estudio del ritual permite acceder a un sistema religioso particular es porque, para citar a Berger (1972), la ritualidad es un mecanismo a través del cual este sistema se legitima en dicho espacio. Es así que un primer elemento a considerar para la comprensión del ritual es su papel en la institucionalización del orden social. Para Berger (1972, p. 49), toda religión supone una legitimación del sistema social y sus desigualdades. Cuando, en el caso de las sociedades no modernas, las instituciones sociales son asimiladas de manera extendida como "equivalencias de lo que ocurre en el mundo de arriba", el sistema religioso se absolutiza eficazmente y sin mayor dificultad. Sin embargo, cuando en las sociedades modernas y seculares el Estado y la religión se bifurcan, es necesaria la recordación continua de lo religioso en la vida cotidiana. Allí reside, precisamente, el papel legitimador del ritual: en reactualizar constantemente la estructura social en la conducta rutinaria de los sujetos.

De este concepto se deducen dos características fundamentales del ritual para Berger: la institucionalización y la continuidad. Todo ritual es, entonces, 
un conjunto de conductas establecidas, hasta cierto punto, de manera oficial por una colectividad y repetidas por fieles que no las han producido. Esto solo es posible si las acciones rituales son reproducidas de manera constante por los sujetos, reactualizando en cada ejecución las jerarquías sociales a través de las cuales ellos asimilaron la necesidad de ponerlas en práctica. Bourdieu (2009, p. 60) explicaba esta urgencia de reproducir los rituales a partir de una "dominación simbólica" ejercida por una clase sacerdotal portadora de los dones de salvación que, a su vez, son el vehículo que permite la acción sagrada del ritual. De esta forma, la práctica repetitiva no solo es necesaria sino que solo en la repetición es posible el mantenimiento, por un lado, de su eficacia salvífica y, sobre todo, de las jerarquías sociales legitimadas por dicha acción.

Así, se entiende al ritual como una conjunción de institución, repetición y legitimación. Sin embargo, ello no resuelve el tema de la plausibilidad (Luckmann, 1973) de la ritualidad. Evidentemente, el ritual no solo se repite porque se impone, sino porque los fieles que lo ejecutan experimentan de algún modo su eficacia. En ese sentido, es útil volver a la noción de "rito de paso" desarrollada por Turner (1988). Para él, los rituales deben entenderse como un proceso orientado a sus fines tanto sociales como individuales. Son "una tipología de situaciones culturalmente reconocidas y estereotipadas, en la que los símbolos utilizados se clasifican según la estructura final de cada situación específica" (Turner, 1988, p. 51). En otras palabras, un ritual es una serie de actos socialmente establecidos, estructuralmente simbólicos y orientados a los fines de su ejecución. Para decirlo en términos más sencillos, los rituales se practican no porque deben ser sino porque sirven para.

$\mathrm{Si}$ es un proceso, se deduce que todo ritual está compuesto por fases o etapas. Turner (1988) distingue tres fundamentales. La primera es la "preliminar", en la cual el sujeto es apartado de la colectividad, simbólicamente, como forma de preparación. En la segunda, denominada "liminal", el sujeto adopta una naturaleza ambigua, límbica, entre la separación de la comunidad y el instante de reinserción a la misma bajo un nuevo estatus o incluso un nuevo ser. Finalmente, en la fase "posliminal", el sujeto ya es cualitativamente distinto y se vincula de manera también distinta a la colectividad. De esta forma, puede deducirse que, para Turner, los rituales, entendidos como procesos o tránsitos, cumplen dos funciones cruciales: son experiencias individuales trascendentes $\mathrm{y}$, a la vez, son mecanismos de socialización en tanto acciones colectivas y procesos de reinserción de un sujeto en la comunidad. 
A partir de lo dicho, se puede construir una noción de ritual como dimensión conductual, mecanismo de legitimación y proceso de (re)socialización de los individuos. Es, ante todo, la práctica religiosa fundamental. No existe religión sin rituales, así como, parafraseando a Weber (1978), no existe sociedad sin acciones sociales. Rappaport (2001, p. 66) lleva más allá la noción de ritual, al situarla como "el acto social básico para la humanidad”. De esta idea se deduce que, contrariamente a lo planteado hasta ahora, el ritual no es solo religioso y que, además, no solo se explica por sus fines. Precisamente, para Rappaport (2001, p. 57), los rituales se explican más por las características formales de su ejecución que por la finalidad que los mueve a ejecutarlos. Es decir, en el ritual, para el autor, la forma condiciona a la sustancia.

Es claro, como diría Berger (1972), que para las ciencias sociales no es importante si la danza de la lluvia genera finalmente que llueva, sino los efectos que la danza ocasiona en la colectividad que la practica. Sin embargo, cuando Rappaport (2001) señala que el ritual es una ejecución donde la forma le confiere el sentido a las acciones, se refiere a que son las formas lingüísticas empleadas y las disposiciones corporales expresadas las que determinan los sentidos que se socializan en una acción ritual. En consecuencia, analizar los gestos, expresiones, posturas y pequeñas ejecuciones de un ritual determinado terminaría siendo el procedimiento necesario para comprender los significados del mismo. Por extensión, si se pretende acceder a la naturaleza de un grupo religioso determinado a través del estudio de la ritualidad, el estudio sistemático de estas formas de ejecución constituiría una alternativa metodológica válida.

De manera general, comprendidas la religión como sistema social coherente y racionalizado que conduce a un estilo de vida determinado, y el ritual como sistema de ejecuciones formales establecidas para legitimar dicho sistema, queda claro que la comprensión de los rituales conduce, sino a entender toda la religión como tal, sí a explicar la continuidad de la misma. Dicho de otro modo, si quisiésemos comprender los factores que inciden en la militancia de cierto sector de la sociedad en una congregación particular, habría que buscar algunos de ellos en las características de la ritualidad practicada al interior de esta. Para enunciarlo de manera más sencilla: qué hacen los fieles dentro de una iglesia que los mueven a asistir religiosamente. Examinemos, para ello, a la confesión religiosa que constituye el objeto de esta investigación: el Movimiento Misionero Mundial. 


\section{El Movimiento Misionero Mundial desde la teoría y la etnografía}

Es deber para las ciencias sociales, y sobre todo para la antropología, considerar, como diría Guber (2011), la interacción entre la perspectiva del investigador y el punto de vista de los actores sociales en la comprensión etnográfica de un espacio determinado. Si tomamos literalmente este principio metodológico, podríamos ingresar a un hondo problema categorial. En principio, oficialmente, el Movimiento Misionero Mundial se inscribe en el Registro Nacional de Confesiones y Entidades Religiosas (Ministerio de Justicia, 2017) como una Iglesia Cristiana Pentecostés. Es decir, por denominación institucional, el Movimiento se autodefine como una congregación inmersa en el complejo universo del pentecostalismo. Sin embargo, para los miembros de la congregación, ellos son, ante todo, cristianos "porque siguen a Cristo". Ahora bien, si a ello le agregamos las caracterizaciones teóricas de las ciencias sociales, el problema categorial se complejiza aún más.

Para comenzar, Marzal (2000) define al pentecostalismo como uno de las cuatro grandes tipologías de congregaciones que conforman lo que denomina el "complejo mundo evangélico". Entre ellas, destacan las iglesias trasplantadas — llamadas por Bastian (1994) como protestantismo histórico- . Son aquellas que surgieron de la Reforma europea del siglo XVI y cuya presencia en el Perú es minoritaria. El segundo grupo lo conforman las iglesias evangélicas, surgidas no en Europa sino en los Estados Unidos y, mucho después, a partir del siglo XIX. Se cuentan entre ellas a la metodista, bautista, presbiteriana, alianzas cristianas, entre otras. El tercer agrupamiento es integrado, precisamente, por las pentecostales, también estadounidenses, pero diferenciadas de las anteriores por la creencia en un Pentecostés continuo y su materialización en un fenómeno conocido como la glosolalia o "don de hablar en lenguas" (Marzal, 2000, p. 36). Finalmente, las iglesias escatológicas son aquellas — como la mormona, adventista o testigos de Jehová- que justifican su existencia en la inminencia del fin de los tiempos (Marzal, 2000, p. 38).

En ese sentido, para Marzal (2000) son pentecostales las iglesias evangélicas que, además, viven constantemente la llegada del Espíritu y la expresan hablando en lenguas. Con mayor profundidad, para Bastian (1997), el pentecostalismo es un fenómeno religioso que puede entenderse desde tres características fundamentales. En principio, son movimientos conversionistas, es decir, marcan una ruptura con las prácticas religiosas anteriores, particularmente las católicas (Bastian, 1997, p. 140). De ello se desprende el carác- 
ter desestructurador del pentecostalismo, que, para usar términos de Berger (1972), rompería con la naturaleza legitimadora de la religión. En segundo lugar, son agrupaciones taumatúrgicas que, básicamente, ofrecen soluciones mágico-espirituales a problemas terrenales y urgentes en escenarios de pobreza, como la enfermedad. Por tanto, la iglesia pentecostal se convertiría, para Bastian (1997), en una alternativa a las dificultades de acceso a servicios de salud. Finalmente, los pentecostalismos suelen ser milenaristas (Bastian, 1997, p. 140). En palabras simples, se orientan a ofrecer el mensaje de un nuevo reino o una nueva era por venir.

Para generalizar la perspectiva de Bastian (1997, p. 139), se entiende al pentecostalismo como una variante religiosa propia de una "cultura de la pobreza". En ese sentido, romper con el orden social anterior, sanar no solo espiritual sino físicamente, y aguardar la llegada de un nuevo mundo constituyen los rasgos que explican la presencia de los movimientos pentecostales en las periferias urbanas. Además de ello, siguiendo también a Bastian (1997), es preciso distinguir entre tres generaciones de estos movimientos. La primera, comprendida entre 1910 y 1940, implica la aparición de los primeros templos pentecostales como resultado de la división de algunas iglesias del protestantismo histórico. La segunda etapa comienza en 1950, con el surgimiento de nuevos pentecostalismos - en plural - de origen latinoamericano, en dos grandes matrices como el Caribe y el Brasil. Finalmente, el tercer periodo se inicia entre 1980 y 1990 y se concentra en la aparición y expansión de grandes congregaciones pentecostales de alcance transnacional y uso constante de medios masivos de comunicación.

Dicho esto, para la teoría tanto sociológica (Bastian, 1997) como antropológica (Marzal, 2000), el pentecostalismo —o los pentecostalismos, en todo caso - son un movimiento asociado a la espectacularidad del ritual, el proselitismo conversionista y la ética rigurosa propia de un mundo que se acerca a su fin. En ese sentido, toda iglesia que cumpla con dichos rasgos podría, al menos teóricamente, ser considerada como pentecostal. Curiosamente, en el caso del Movimiento Misionero Mundial ocurre un escenario distinto y acaso inverso. La institución como estructura oficial se autodenomina como "pentecostés", los fieles se agrupan bajo un rotulo más general y tal vez ambiguo: "cristianos". Y, finalmente, para los estudios de la religión, no constituiría una congregación pentecostal en sentido estricto.

Basándonos en el estudio del que surge esta investigación (Rolleri, 2017a), es posible afirmar que el Movimiento Misionero Mundial cumple solo par- 
cialmente con los rasgos básicos del pentecostalismo. En primer lugar, se trata, en efecto, de una congregación que se expande a partir del mensaje de conversión, en el que la cadena de comunicaciones Bethel Televisión cumple un papel fundamental y se acentúa en cada culto a través de la práctica continua de un ritual llamado como "invitación" o "paso al altar". Sin embargo, no se trata de una iglesia donde los rituales taumatúrgicos desempeñen un rol significativo. No se desarrollan jornadas de sanación, excepto en ocasiones muy específicas, y la curación de enfermedades no suele ser parte de la temática de los cultos ni de los fines usuales de los rituales practicados en el templo. Finalmente, el mensaje milenarista no es muy significativo en los cultos, a pesar de que, en palabras de los pastores de la congregación, se identifiquen como una alternativa a un "mundo en crisis". En otras palabras, el Movimiento es conversionista, no es taumatúrgico y es relativamente milenarista.

Por otro lado, en cuanto a la caracterización de Marzal (2000), habría que decir que el Movimiento solo coincide con uno de los rasgos que definen al pentecostalismo. Las manifestaciones del "pentecostés continuo" que señala Marzal (2000) son resignificadas bajo un principio doctrinal de la congregación, denominado como "bautismo en el Espíritu", que consiste en una señal de elección con el que la divinidad marca, por decirlo de algún modo, a los fieles más involucrados con la fe, la ética o la congregación. Sin embargo, este bautismo no es continuo ni se manifiesta necesariamente en la glosolalia, segundo rasgo esencial del pentecostalismo. A partir de ello, puede deducirse que, dadas las categorías de Marzal (2000), el Movimiento Misionero Mundial no se ajustaría a los rasgos distintivos de una iglesia pentecostal como tal.

En cuanto a las etapas de los movimientos pentecostales, el Movimiento Misionero Mundial se situaría entre la segunda y la tercera. Surge en la década de 1950, en uno de los focos protestantes latinoamericanos como el Caribe, como una iniciativa de predicadores exintegrantes de las Asambleas de Dios, congregación fundadora del pentecostalismo de primera generación (Bastian, 1997). Sin embargo, coincide plenamente con los rasgos de la tercera etapa, fundamentalmente, la presencia masiva de la congregación en medios audiovisuales de comunicación. De acuerdo con cifras de la iglesia (Rolleri, 2017a), el Movimiento reúne a cerca de dos mil templos, cientos de estaciones de radio, una gran cadena de televisión, medios impresos, aplicaciones doctrinales para teléfonos móviles y una presencia significativa en setenta y un países del mundo. En consecuencia, podría decirse, para resumir, que el Movimiento es una iglesia conversionista, espiritualista — pero no taumatúrgica-, cuasimi- 
lenarista y, sobre todo, massmediática, pero no completamente pentecostal, pese a que oficialmente se considere como tal.

A fin de comprender, con mayor profundidad, el carácter complejo y acaso híbrido de esta congregación, retomando el trabajo que origina este estudio (Rolleri, 2017a), se propone una descripción del Movimiento Misionero Mundial a partir de las cinco dimensiones de lo religioso que desarrolla Marzal (2002). En principio, en cuanto a la organización social, es preciso caracterizar a esta congregación como una estructura social jerárquica que se establece a partir de una lógica corporativa, a la manera de una gran empresa. Es presidida por una junta de oficiales mundiales, todos latinoamericanos, que solo pueden ser elegidos por la propia junta, se reúnen algunas veces al año y cumplen la función de supervisores nacionales en los países que se les asignan. Debajo de ellos, se encuentran los oficiales nacionales, elegidos por la junta mundial, de funciones similares a esta, pero a nivel local, y encargados de la administración de la iglesia de un determinado país. Según la Constitución de dicha congregación, las funciones de estas jerarquías son directamente otorgadas por la divinidad, lo que, a decir de Berger (1972), legitima y absolutiza su supremacía.

A nivel local, por su parte, cada iglesia nacional es dividida en presbiterios, que son las unidades administrativas fundamentales de la congregación. Tiene, además, una extensión variable y relativa a la densidad de fieles que reúne. Así, un presbiterio puede ser una ciudad o país entero, o un distrito puede contener a más de un presbiterio, según la cantidad de sus miembros. Finalmente, esta unidad administrativa puede reunir a distintas iglesias y anexos (templos menores a cargo de un hermano sin formación de pastor), y está a cargo de un presbítero, que es el pastor de la iglesia central de la jurisdicción. Vale la pena mencionar que cada iglesia se autosostiene con recursos generados por sus propios fieles y concede un diezmo al presbiterio. Este se sostiene con los ingresos generados por el templo central y los aportes de los otros templos de su jurisdicción, y contribuye con un diezmo a la iglesia nacional, que a su vez aporta un diezmo a la corporación mundial. De esta forma, contrariamente a lo afirmado por Marzal (1988) sobre el mundo evangélico peruano, no es la solidaridad mecánica durkheimiana, sino la conjunción de una jerarquía rígida y sacralizada, además de una estructura corporativa, la base de la organización social del Movimiento Misionero Mundial.

Por otro lado, en cuanto a las creencias, segunda dimensión de la religión desarrollada por Marzal (2002), es preciso identificar tres dogmas compartidos por esta congregación en todos sus templos. Primero, la congregación 
enfatiza en la salvación del sujeto por medio de la fe. En palabras simples, la creencia en los dogmas promovidos por la congregación facilita la obra divina del nuevo nacimiento del creyente y su liberación del mundo hostil que lo rodea. En segundo lugar, puede citarse al "bautismo en el Espíritu", que es entendido como una señal de elección del Espíritu Santo que recae sobre el creyente y puede hacerlo "hablar en lenguas". Sobre este punto, a diferencia de la mayoría de los pentecostalismos, los fieles del Movimiento aseguran que este bautismo generalmente ocurre en momentos de oración en privado y hasta una sola vez en la vida. Por tanto, no se asemeja a los actos de glosolalia continua que se suelen apreciar en las agrupaciones pentecostales. Finalmente, los fieles del Movimiento creen en la inspiración de las Escrituras, es decir, como la mayoría de grupos del protestantismo, asumen a la Biblia como la única fuente de las verdades religiosas.

La tercera dimensión de la religión, siguiendo la definición de Marzal (2002), es la ética. Para el caso del Movimiento, esta se encuentra comprendida en un libro pequeño, de unas setenta páginas, que reúne veinticinco lecciones fundamentales y es distribuido a toda la congregación al precio de siete soles. Se titula Instrucciones bíblicas para recién convertidos (Ortiz, 1980), pero es conocido por los fieles, genéricamente, como la Doctrina. En resumen, estas veinticinco lecciones se basan en la internalización de una ética muy rigurosa, entendida como la disciplina, y expresada en imperativos de privaciones, compromisos y contribuciones. En primer término, por la Doctrina los fieles son impulsados a una suerte de ascetismo intramundano (Weber, 1978), que los mueve a renunciar a la vida nocturna, el consumo de sustancias demonizadas (alcohol, tabaco, drogas), el consumo de contenido audiovisual que no edifique, la vida sexual extramarital y la militancia política explícita. En segundo lugar, la Doctrina los mueve a comprometerse plenamente con los objetivos de la congregación, lo que se expresa, por ejemplo, en la asistencia al templo los siete días de la semana y, en el caso de los domingos, tanto en la mañana como en la tarde. Por último, la Doctrina hace que los fieles asuman con gozo la rigurosidad de la ritualidad económica de la congregación. Así, contribuyen en diezmos, ofrendas, marchas, campañas, aires libres y lo hacen con una satisfacción inusitada.

La cuarta dimensión de lo religioso que puede contribuir a la comprensión del Movimiento Misionero Mundial es el sentimiento. Este elemento, aunque poco estudiado en ciencias sociales, resulta esencial para aproximarse a esta congregación, en tanto, la experiencia ritual es, ante todo, entusiástica. 
Particularmente, a manera de ejemplo, puede citarse la participación de los fieles del Movimiento en el ritual central del culto dominical: el paso al altar. De manera breve, puede describirse a este acto como el efecto del mensaje religioso diario en la emotividad de los fieles. Al finalizar la prédica, se suele invitar a los hermanos a orar y, en medio de este acto, se pide que pasen a los pies del altar los que deseen iniciarse en la congregación, hacerle un pedido especial a Dios o reconciliarse con él. Al margen de los motivos, en promedio, el $70 \%$ de la congregación se acerca al altar a orar intensamente, con los brazos en alto, las palmas hacia arriba, el rostro compungido, los ojos lacrimosos y una voz hondamente quejumbrosa. Lo que se ha podido comprobar en la investigación que origina este trabajo es que este ritual es el eje emocional y hasta estructural del proceso ritual del culto, lo que evidencia la relevancia del sentimiento en las prácticas religiosas del Movimiento.

\section{La ritualidad del Movimiento: entre la fe y la economía}

La quinta dimensión del fenómeno religioso, de acuerdo con Marzal (2002), es el ritual. Retomando lo planteado por Turner (1988), comprender los rituales de un grupo social es una forma eficaz de acceder a su estructura y naturaleza. Y si consideramos, como propone Rappaport (2001), que el ritual es el acto social fundamental de los seres humanos, resulta esencial en el análisis de las prácticas religiosas para un acercamiento sólido a la lógica de esta congregación. En ese sentido, si bien, evidentemente, no constituye la única forma de ritual practicado cotidianamente en el Movimiento, para la presente reflexión, se tomará, a manera de ilustración, una variante ceremonial desarrollada intensamente en dicha iglesia. Se trata de la ritualidad socioeconómica de la congregación. Concretamente, se propondrá una descripción y análisis, desde la perspectiva de los fieles, de cuatro experiencias rituales significativas del Movimiento: el ritual de las ofrendas, la marcha proterreno, la marcha del dólar y, finalmente, el ritual de preparación de los aires libres.

\subsection{El ritual de las ofrendas}

Es un hecho común en el mundo religioso la destinación de los momentos finales de cada celebración ritual a las contribuciones económicas. Ahora bien, considerando, como se explicó anteriormente, que el Movimiento Misionero 
Mundial es, además de una iglesia, una gran organización corporativa, resulta comprensible la presencia de rasgos específicos de esta parte de los cultos. En líneas generales, para el caso de esta congregación, la actividad del recojo de ofrendas se encuentra altamente ritualizada. Así, la ubicación de esta ceremonia en el programa habitual del culto, el lenguaje y la música empleados, las disposiciones corporales de los participantes y la ejecución propiamente dicha suponen la coexistencia de dos procesos yuxtapuestos. Por un lado, visibilizan la utilización de mecanismos estratégicos de parte de la corporación a la manera de decisiones empresariales y, por otro lado, constituyen una forma de relación simbólica entre los sujetos, la congregación e incluso la divinidad.

A manera de relato, el recojo de ofrendas consta de tres momentos diferenciados. El primero de ellos podría denominarse como el "tránsito". Cabe precisar que, en el proceso del culto, la experiencia ritual de las ofrendas se sitúa inmediatamente después de la fase liminal (Turner, 1988) de la reunión: el paso al altar. Después de la sensación de renovación y contacto con lo sagrado que constituye este paso, el estado de ánimo generalizado en el templo suele ser de entusiasmo e incluso euforia. Esta sensación es evidenciada en el cántico posterior, generalmente interpretado con diversos instrumentos de percusión, palmas, vítores, saltos y zarandeos. Al finalizar este tránsito de una contrición intensa a un entusiasmo exultante, puede entenderse que la predisposición a donar se incremente. Y ello, claramente, se evidencia en la recolección de las ofrendas, pues al menos el $90 \%$ de los asistentes contribuye en cada jornada.

El segundo momento puede rotularse como de "invitación y justificación”. Al terminar el cántico festivo, toma un lugar en el altar el pastor auxiliar del templo que, durante el tiempo de esta etnografía, era Felipe. Esta autoridad de la iglesia, de portentosa voz, anuncia con tono entusiasta que inicia "la hora más alegre del culto". La respuesta de los fieles, en masa, suele ser de vítores, palmas y expresiones como "amén", que suele expresar un sentido de afirmación o asentimiento en el contexto del ritual. El pastor Felipe continúa su discurso justificando la importancia de contribuir con las ofrendas y enfatizando en el uso que la iglesia hace de estas. Un hecho recurrente es sustentar esta contribución en la premisa de que "aquí nadie se queda con el dinero". A manera de ejemplo, se transcribe una de estas alocuciones: ${ }^{2}$

2 Transcripción del culto del domingo 15 de enero del 2017, durante una visita etnográfica realizada al templo central de Pueblo Libre (presbiterio N. ${ }^{\circ} 7$ del Movimiento Misionero Mundial). Este fragmento ha sido tomado de la investigación que origina el presente artículo (Rolleri, 2017a). 


\section{Pastor Felipe:}

Hermanos, llegó la hora más alegre del culto [se escuchan algunos vítores y muestras de entusiasmo]. A ver, repítele al hermano que está a tu lado. Dile: "Llegó la hora más alegre del culto" [las personas voltean a los lados y se dicen eso entre sí]. Es el momento de ofrendar y de dar los diezmos. ¿Quiénes dicen "amén"? [los fieles responden a una sola voz "amén"]. Hermanos, ustedes saben que la iglesia tiene gastos que asumir. Hay que pagar el local, la luz, el agua. Hay que hacer campañas, aire libre y muchas cosas más para llevar la palabra de Dios a todo Pueblo Libre, Breña, Jesús María y los distritos del presbiterio. Y todo eso cuesta, hermano. Nada es para los bolsillos de los pastores. Es más, nosotros los pastores también ofrendamos como ustedes. Porque el dinero no alcanza, hermano. Por eso, con la alegría que Dios ha puesto en tu corazón en esta mañana, dale al Señor de lo mucho que él te ha bendecido. No lo que te sobre, hermano, sino lo que el Señor mueva a dar en tu corazón. Vamos a unirnos en oración.

El tercer momento del ritual de "recojo de ofrendas" es la ejecución propiamente dicha. Esta inicia con una oración dirigida por el pastor aludido, a través de la cual se pide a la divinidad que bendiga las contribuciones y a los hermanos que las aportan. Se pide que estas se multipliquen y permitan cubrir las necesidades de la congregación. Mientras los fieles permanecen con los ojos cerrados y los brazos en alto, en posición de oración, cuatro miembros de la iglesia, delegados para tal función, ya se han ubicado en cuatro zonas del templo para extender las alforjas donde se depositará la ofrenda. Mientras los encargados se desplazan ordenadamente por cada fila, los hermanos entonan una alabanza de carácter festivo, entusiasta, con palmas, saltos y zarandeos. Así, de manera explícitamente alegre, los hermanos asumen no solo el compromiso sino el gozo de donar. Cabe precisar que esta alegría no es espontánea, sino hasta cierto punto planificada, pues es recurrente en cada sesión ritual. La música, en esa lógica, cumple la función de estimular la contribución y revestirla de un significado festivo, no impositivo. De esta forma, las ofrendas trascienden la idea de imperativo ético: se ritualizan.

A manera de análisis de esta ejecución, lo primero que debe considerarse es la ubicación estratégica del recojo de ofrendas en el culto. Si entendemos a este como un proceso ritual en el sentido de Turner (1988), se asume que cada momento del culto supone un rito encadenado al anterior y al que le sucede. A partir de ello, el situar a la ofrenda inmediatamente después del paso al altar describe una cierta intencionalidad de la congregación en tanto corporación. Después de este ritual, la predisposición de los fieles se incrementa ostensiblemente: tras la fase liminal, el sujeto adquiere un estatus distinto 
para sí mismo y para la congregación. La plausibilidad (Berger, 1972) de los imperativos éticos se acentúa, pues los fieles entienden que cualquier forma de desprendimiento, incluso el económico, es compensado y hasta superado por los beneficios simbólicos que recibe en el culto. Y ello se hace más visible tras la emoción del paso al altar. En palabras simples, después de este rito, el fiel es capaz de hacerlo todo por su congregación.

A ello debe sumarse la cuestión de la música, el lenguaje y la disposición corporal que acompañan a la ejecución de la recolección. Las canciones que se presentan durante el recojo de ofrendas suelen expresar la exaltación del triunfo de Dios frente al mal y, por extensión, el de su comunidad frente a la sociedad exterior. Como asegura Bastian (1997), esta manifestación de "victorias" es frecuente en los movimientos pentecostales y ello se hace evidente en las interpretaciones de los fieles. El hecho de vitorear mientras se canta, de emplear numerosos instrumentos de percusión, de permitir zarandeos del cuerpo, etc., no solo suponen la ruptura con lo ceremonial del culto, sino asocian la entrega de la ofrenda a una fiesta ritual. La expresión victoriosa del cántico puede asociarse a la idea de beneficio, de ganancia, que experimentan los fieles al donar. En cierto modo, desprenderse no es perder sino mostrar que se ha ganado.
Alberto:
Un cristiano debe ofrendar, debe diezmar con gozo. Hay gente del mundo que dice que en las iglesias le quitan su dinero a las personas, que se aprovechan. Eso no es cierto. Tal vez en otros sitios. Acá los hermanos colaboramos con alegría, con libertad. Y el dinero no es para que nadie se lo quede. Lo que colaboramos es para la obra del Señor. Es simple: Dios te bendice y tú le das a la iglesia de lo que él te da. Así Dios te sigue bendiciendo. Cuando tú das, verás que el Señor te bendice y nunca te falta. El Señor nunca desampara al dador alegre.

Se construye, de esta forma, una relación de reciprocidad en la contribución económica $\mathrm{y}$, como consecuencia de ello, la legitimación del sistema ético que rige al Movimiento adquiere mayor eficacia. Por un lado, se aprecia una asociación entre la ética rigurosa del grupo religioso y su predisposición constante al desprendimiento económico. En términos sencillos, se ofrenda diariamente porque "es bueno, es correcto y es de cristianos". En segundo lugar, se evidencia una relación entre el desprendimiento económico y la prosperidad en el futuro inmediato. Es decir, se ofrenda diariamente porque "si se hace, Dios te bendice". De esta manera, se conjugan dos elementos básicos de la 
ritualidad socioeconómica del Movimiento. El recojo de ofrendas es ritual por la forma y, como señala Rappaport (2001), la forma condiciona los sentidos en el rito. A su vez, esta ceremonia es planificación estratégica, es decir, es un procedimiento que institucionaliza los procedimientos organizacionales de la iglesia como bienes simbólicos en el sentido de Bourdieu (2009). En otras palabras, se ratifica la política corporativa.

\subsection{La marcha proterreno}

A diferencia del ritual anterior, esta expresión híbrida entre práctica religiosa y estrategia institucional no se desarrolla en todas las sesiones cultuales. Para contextualizar su existencia, es preciso afirmar que el análisis de sus ejecuciones se remite, como en toda la investigación, al templo de Pueblo Libre. No obstante, en cuanto el pastor principal, a quien llamamos Willy, suele justificar su desarrollo con expresiones como "la iglesia nos ha dicho que ya nos toca marcha proterreno", se asume que constituye un ritual institucionalizado en la organización para ocasiones específicas. En el caso de esta sede, se organizan los domingos, una vez al mes en promedio, y se comunican con unos días de anticipación. El propósito de la misma se encuentra contenido en el nombre: recolección de contribuciones para la adquisición de un nuevo terreno que permita extender la labor de la iglesia.

Como se mencionó en el segundo apartado, todas las iglesias son económicamente autónomas. Por tanto, la responsabilidad de expandir la cantidad de locales dentro de un presbiterio recae, sino de manera exclusiva, al menos mayoritariamente en el presupuesto de la propia jurisdicción. Además, debe considerarse que uno de los imperativos éticos más significativos de la congregación es el compromiso con lo que se denomina la obra de Dios, es decir, la expansión del Movimiento en cantidad de templos, de fieles, de plataformas mediáticas y, presumiblemente, también en ingresos. En esa lógica, resulta, dentro del universo estructural y simbólico de esta iglesia, una necesidad relevante la realización de procesos específicos de recaudación para la adquisición de un predio que permita el crecimiento de la congregación en la zona. Es el caso particular de la marcha proterreno.

En cuanto a la planificación de la misma, cabe mencionar que, durante el periodo de realización de esta etnografía, entre el 2016 y 2017, existía la propuesta oficial de adquirir un predio de gran extensión en el cruce de las avenidas Brasil y General Vivanco, en Pueblo Libre. Con dicha finalidad, se reali- 
zaba esta marcha el segundo o tercer domingo de cada mes. La participación implicaba la donación de un mínimo de diez soles que no eran obligatorios para todos los asistentes, pero, por la rigurosidad ética de la congregación, sí existía una imposición implícita para el caso de los miembros oficiales de esta. Cabe precisar que solo se aceptaban aportes en billetes, no en monedas. A fin de comprender los sentidos de esta práctica ritual, resulta fundamental no solo aproximarse a los fines institucionales de la misma, sino a las formas de ejecución en sí.

Al igual que en el caso de las ofrendas, se distinguen tres momentos concretos en la realización de la marcha. El primero de estos es el "tránsito". Si describimos este ritual desde su conexión con el momento anterior, es importante mencionar que es precedido por canciones de alabanza. Como ya se ha analizado, estas se caracterizan por su ritmo festivo, el empleo de diversos instrumentos musicales, la temática victoriosa en la letra de las canciones y el acompañamiento con aplausos, vítores y algunas formas de danza. De ello se deduce que el estado festivo que caracteriza al recojo de ofrendas se extiende a la realización de la marcha, inmediatamente posterior. En ese sentido, el donar con alegría parece ser un rasgo esencial de la ritualidad económica de la congregación.

El siguiente momento del ritual, al igual que en el caso de las ofrendas, es la "justificación-invitación". Se distinguen, a su vez, dos secuencias en esta parte de la ceremonia. En el primero, el pastor Willy, presbítero de Pueblo Libre hasta febrero del 2017, solía explicar la importancia de contribuir con la marcha para que "Dios nos bendiga con una iglesia grande". En el siguiente, a través de una oración colectiva, se sacralizaba la ejecución a pedir a la iglesia por la vida económica y laboral de cada uno de los hermanos, y por la multiplicación de lo recaudado. Resulta relevante señalar que, cuando se elevaba la plegaria por el crecimiento de lo que se va a obtener, la contrición del rostro, la profusión de lágrimas y la sonoridad de la voz quejumbrosa se hacía aún mayor. Es decir, la intensidad colectiva de la oración validaba, de alguna manera, el pedido, ante todo, de naturaleza económica.

Finalmente, el proceso de ejecución de la marcha supone planificación logística y simbolismo ritual. Mientras las personas oran por la provisión, se coloca un ánfora a los pies del altar. Al terminar, empieza a sonar una canción de alabanza que, al parecer, es un componente institucionalizado de interpretación. Se trata de la canción "Oye, Moisés, dile a mi pueblo que marche, que marche, que marche y que no se detenga". Esta canción, que consiste en un 
único estribillo de tres versos, es repetida ininterrumpidamente mientras las personas van marchando desde sus asientos hacia los pies del altar. En este lugar se situaba el ánfora, que, básicamente, era un balde con una bolsa negra en su interior, y un holograma con el logotipo de Bethel Televisión en su exterior. De cierta forma, el empleo de la imagen característica de la plataforma de comunicaciones de la iglesia oficializa la ceremonia ritual y legitima el carácter corporativo de la misma.

Primero, las mujeres comenzaban a desfilar hacia el ánfora. En esta dejaban un billete de diez, veinte o cincuenta soles, mientras cantaban la alabanza, esbozaban algunas formas de danza o acompañaban la canción con aplausos. Luego seguían los varones, que repetían el procedimiento, con similar alegría. Entre hombres y mujeres, alrededor de cincuenta personas se acercan a participar de la marcha con billetes de diez soles como mínimo. De acuerdo con el pastor Willy, esta ofrenda está destinada a "reunir el dinero para el terreno del nuevo templo en la avenida Brasil que la iglesia desea adquirir para que crezca la obra de Dios". De ello se deduce, como en el caso del ritual anterior, que la conjunción entre la plausibilidad del imperativo ético de compromiso, altamente difundido en la congregación, es asimilada por los hermanos a la manera de una relación recíproca entre el fiel y la divinidad.

Óscar:

La iglesia no les quita el dinero a los hermanos. Los hermanos contribuyen a que la iglesia crezca, que llegue a más lugares. Así más gente como nosotros puede conocer el mensaje de Dios y cambiar su vida como lo hicimos nosotros. Si todo lo que tenemos y todo lo que somos es por el Señor, ¿cómo no apoyar para que otros tengan lo que tenemos y sean lo que somos? Sería egoísta y eso no es de cristianos.

Si consideramos que todas las contribuciones en la marcha proterreno son de diez soles como monto mínimo, y que no es inusual ver a algunos miembros depositar billetes de cincuenta, lo recaudado mensualmente sería un estimado de mil soles. Si tenemos en cuenta, además, que, en algunas ocasiones, este ritual se celebra tanto en el culto dominical de la mañana como en el de la noche, la cifra podría ser todavía mayor. Lo cierto es que, más allá del monto recaudado y de que, probablemente, sean necesarias muchas marchas para adquirir el terreno de unos $300 \mathrm{~m}^{2}$ que se pretende, la marcha proterreno es una evidencia más del hibridismo entre la práctica estrictamente ritual y la estrategia institucional de tipo administrativo. Un rasgo que, aparentemente, 
es hegemónico en la ritualidad económica de esta congregación y va a tener en la marcha del dólar a su manifestación más significativa.

\subsection{La marcha del dólar ${ }^{3}$}

Es, probablemente, el ritual económico más complejo, relevante y simbólico de la congregación. Además, constituye un rasgo distintivo de esta, pues solo se practica en el Movimiento Misionero Mundial, se realiza de manera estrictamente regular e incluso suele televisarse a través de Bethel Televisión. En cuanto se trata, ante todo, de una marcha, consiste en el desplazamiento ordenado, festivo y ritualizado de los fieles hacia los pies del altar para depositar contribuciones económicas en un lugar previamente asignado. Sin embargo, las características de la planificación, la forma de la ejecución y el propósito corporativo del ritual son distintos y hacen, por tanto, de esta marcha, una experiencia cualitativamente diferente a las otras formas de ritualidad económica. Por ello, tanto para la descripción como para el análisis, se consideran como variables a la planificación, la ejecución y los fines de esta ceremonia periódica.

En principio, habría que afirmar que esta práctica ritual destaca por su sofisticada preparación logística. Si bien se desarrolla, estrictamente, todos los primeros domingos de cada mes, es anunciada desde la semana anterior. Seguidamente, desde cinco días antes, se dispone la participación de una hermana encargada, ubicada en una mesita a la entrada del templo, para la venta de billetes de un dólar con el logotipo del Movimiento Misionero Mundial y Bethel Televisión. Durante toda esa semana, los fieles pueden adquirir la cantidad de billetes que les sea posible al precio en soles de un dólar, según el tipo de cambio vigente. Durante esta investigación, se pudo comprar estos billetes a S/ 3.30, S/ 3.40 o S/ 3.50. De esta manera, llegado el domingo, resulta muy probable que todos los miembros de la iglesia y asistentes regulares a los cultos hayan adquirido, en el mejor de los casos, más de un billete de dólar.

Hasta allí, solo podría afirmarse que la marcha del dólar es un mecanismo de recaudación económica. Sin embargo, el primer domingo del mes, la ejecución de esta actividad adquiere un simbolismo ritual de gran relevancia. En principio, los billetes no vendidos se ofertan al inicio del momento del culto

3 Se ha publicado anteriormente un análisis particular de este ritual (Rolleri, 2017b). Para referencias más específicas acerca de la marcha del dólar, puede consultarse dicha investigación y la tesis (Rolleri, 2017a) que dio origen a la misma. 
asignado para ello, inmediatamente después de la recolección festiva de las ofrendas. Vale la pena indicar que, los días de marcha del dólar, el templo suele lucir mucho más lleno, pues participan de ella algunos grupos representantes de las iglesias y anexos del presbiterio, debidamente identificados con pancartas. Al terminar de venderse los billetes asignados por la congregación nacional, se inicia el proceso ritual de la marcha con la oración colectiva de propósito económico que caracteriza a estas formas de ritualidad.

Finalizada la oración, comienza la marcha propiamente dicha. Las representaciones de las iglesias y anexos, los niños, las mujeres, los hombres y, finalmente, los pastores, siempre en ese orden, se acercan hacia los pies del altar. Allí se ha apostado un ánfora de similares características a la marcha proterreno, donde son depositados todos los billetes de un dólar que los fieles han logrado adquirir. Estos, además de los logotipos ya mencionados, incluyen en la parte superior un código a manera de talonario, a fin de contabilizar lo recaudado por la congregación en cada jornada. Al igual que en otras formas de ritos económicos, los hermanos se acercan al ánfora cantando, aplaudiendo y esbozando pasos de danza mientras depositan sus billetes. Al finalizar, todos los fieles, incluidos los niños, ancianos y visitantes esporádicos, ya sea por compromiso individual o por presión de grupo, ya sea para dejar uno o muchos billetes (se forma una cierta "competencia" entre miembros, sobre todo varones jóvenes, por "dejar más"), sin excepción alguna, se acercan a contribuir. Solo por tentar un monto, cada marcha debe recaudar, siendo austeros, alrededor de quinientos dólares.

El propósito de este rito económico es siempre explícito: recaudar fondos para el sostenimiento de Bethel Televisión. Se pone en práctica el mismo día en todos los templos centrales de los ciento cuatro presbiterios ${ }^{4}$ de la congregación, lo que implica que, por decirlo de algún modo, su ejecución constituye una política corporativa del Movimiento. No obstante, en su desarrollo concreto, la marcha del dólar es internalizada de manera diversa por los fieles que participan, con la inusitada alegría ya descrita, en su realización. Por un lado, en términos de los pastores, este ritual refleja el compromiso de los hermanos para con los objetivos de expansión de la iglesia, significados como la obra de Dios.

4 Es preciso indicar que, hasta abril del 2017, cuando concluyó la investigación etnográfica que dio origen a este trabajo, la cifra de presbiterios en los que se divide el Movimiento era de ciento cuatro. Considerando la estrategia de expansión que caracteriza a esta congregación, es muy probable que, para la fecha de publicación de este artículo, la cantidad de zonas sea algo mayor. 


\title{
Pastor Marcos:
}

La marcha del dólar tiene la finalidad de ayudar a través de un aporte económico que hacen cada mes todas las iglesias y que va dirigido a Bethel. Bethel no es solo una radio, sino es una red de comunicaciones. Mantenerla es un gasto enorme, hay que mantener antenas, satélites, pagar los sueldos de más de cien personas. La marcha solo trata de cubrir una parte, que son los sueldos del personal, que casi nunca se llegan a cubrir. Siempre la iglesia tiene que estar dando aportes adicionales a Bethel, porque no es suficiente. Hay iglesias que aportan más y otras menos, pero entre todas tratamos de darle ese sustento que Bethel necesita.

A su vez, para los miembros de la congregación, esta acción ritual es comprendida en términos de una reciprocidad cuantitativa y cualitativamente desigual en favor de ellos. Si bien responde a un compromiso que, desde luego, es resultado de la internalización de los objetivos corporativos de la organización a través de la Doctrina, es entendido por los hermanos como un desprendimiento justificable y valioso tanto para ellos como para las personas que todavía no integran su congregación. La expansión de la iglesia es vista por los fieles como un triunfo en la guerra contra el mal que libra su comunidad religiosa y una contribución a la obra de Dios que, a su vez, permitió que ellos accedieran a los dones de salvación (Bourdieu, 2009) que solo ostenta su organización. En ese sentido, la conjunción de un compromiso valorado positivamente y una lógica de reciprocidad que los favorece explican la racionalidad que mueve a los fieles a donar constantemente en esta forma de estrategia corporativa ritualizada.

\begin{abstract}
Alberto:
Aunque tú veas que todos salen a marchar, nadie los obliga. Los que somos cristianos sabemos que cada mes se hace el recorrido para Bethel. Sabemos de la importancia de Bethel en la obra de Dios. Si no fuera por la radio o por la televisión, mucha gente no habría conocido la palabra y no habría tenido la posibilidad de cambiar su vida. En este momento, mientras tú y yo hablamos, puede que en una casa, cambiando y cambiando de canal, un hombre o una mujer llegue a Bethel, escuche el mensaje del pastor González y se convierta a Cristo. No te imaginas la alegría de pensar que, por el dólar con el que yo colaboro mes a mes, un alma se gana para Cristo. Imagínate, hermano. Si a mí me paso, saber que por mi apoyo, el Espíritu se puede mover en alguien, eso paga todos los dólares que yo pueda donar.
\end{abstract}

\subsection{La preparación de los aires libres}

Esta misma conjunción entre lo corporativo y lo simbólico, entre lo gerencial y lo ritual, entre lo material y lo sagrado, es visible en las formas de planifi- 
cación de eventos al interior de la congregación. Para aclarar términos, por "aire libre" se entiende, al interior del Movimiento, a un gran culto a puertas abiertas, desarrollado en la vía pública - puede ser en una losa deportiva o un parque del distrito-, durante toda una jornada de sábado (9 a. m. a 9 p. m.). El propósito de esta celebración es ritual y proselitista al mismo tiempo: atraer adeptos a la congregación o, en términos endógenos, ganar almas para Cristo. Para ello, se establece un acuerdo con la municipalidad para la utilización del parque correspondiente o se alquila la losa deportiva prevista, según sea el caso. Se monta un estrado con el que ya cuenta la iglesia y se dispone de toldos, decorado y otros recursos logísticos, además de comisiones de hermanos comprometidos por entero en su realización.

En términos generales, un aire libre es un culto de día completo realizado en la calle. Incluye presentaciones teatrales, títeres para niños, presentaciones musicales, juegos y distintos momentos cultuales durante toda la jornada. No obstante, para el presente análisis, el objeto de estudio no es el aire libre en sí, sino el proceso ritual de preparación para su ejecución, es decir, la recaudación ritualizada de fondos entre los fieles. Sobre todo en este caso, a ojos externos, la dinámica de captación de recursos parecería ser demasiado terrenal para ser definida como práctica religiosa. Sin embargo, partiendo de que un ritual es, ante todo, un conjunto de ejecuciones formales no establecidas por quienes los realizan (Rappaport, 2001), las disposiciones corporales, los lenguajes, la periodicidad y las formas de organización colectiva suponen su adecuación a dicha definición.

La planificación de un aire libre suele desarrollarse al finalizar el culto nocturno del jueves anterior a la jornada. Se ejecuta inmediatamente después del ritual del recojo de ofrendas, lo que supone el mantenimiento del ambiente festivo y de gran disposición a donar que caracteriza a los momentos finales de la reunión. La noche del miércoles ya se anuncia que el fin de semana "habrá aire libre" y, por tanto, se va a requerir de la colaboración en tiempo y dinero de los hermanos. Como suele ocurrir en todo ritual económico del Movimiento, se inicia con una justificación-motivación, que tiene por fin sustentar racionalmente la necesidad de contribuir y alentar emotivamente a la participación en sí. Para iniciar la experiencia, se fija el monto que se desea recaudar en ese momento. Usualmente fluctúa entre los quinientos y ochocientos soles, de acuerdo a si se necesita alquilar un espacio o no. Como todo ritual, se inicia con una oración colectiva, que legitima y sacraliza el procedimiento de recaudación. 
La lógica de la preparación de un aire libre es muy similar a la de los otros ritos económicos. Se conjugan música festiva, palmas, vítores, zarandeos y el movimiento de las alforjas entre los asientos destinados a los fieles. No obstante, a ello se le agrega un elemento estimulante: una competencia entre hombres y mujeres por acumular la mayor cantidad de aportes. Al recorrer cierta cantidad de asientos, el encargado de extender las alforjas a los hermanos es invitado por el presbítero a revelar la cantidad que se va acumulando. Así, el entusiasmo ritual, la competencia entre géneros y la estrategia corporativa confluyen para ejecutar una práctica religiosa híbrida que permite a las iglesias autosostener las actividades proselitistas de su comunidad y, a la vez, posibilita que los fieles asuman como propios los objetivos corporativos. El entusiasmo se convierte, en cierto modo, en el móvil que impulsa a los hermanos a realizar la política corporativa con alegría, compromiso y, hasta cierto punto, devoción ritualizada.

En términos económicos, la experiencia etnográfica evidencia que la meta de aportes no suele completarse y se hace necesaria la contribución pública del presbítero, que es vitoreada por los fieles. No obstante, destaca la velocidad con la que los miembros de esta congregación recolectan alrededor del $90 \%$ de lo esperado. Además, resulta relevante verificar que las donaciones suelen ser en billetes, casi nunca en monedas. Finalmente, no puede negarse que tanto la lógica de reciprocidad simbólica y material, así como la internalización de los objetivos expansivos de la congregación, permiten que este ritual económico sea un mecanismo eficaz de captación de recursos para la iglesia. Parece ser que, dentro de la racionalidad que moviliza la ritualidad del Movimiento, no solo se dona, se dona con gozo. Y los fieles no solo se desprenden de dinero, se benefician haciéndolo.

\section{Conclusiones}

- El Movimiento Misionero Mundial evidencia dos de los rasgos significativos de la complejidad del panorama religioso peruano. En primer lugar, destaca por su hibridismo, pues, pese a ser nominalmente pentecostal, en su cotidianidad solo se reflejan parcialmente algunos de los rasgos distintivos del pentecostalismo latinoamericano: el culto entusiástico y la dinámica conversionista. En segundo término, sobresale por la confluencia de propósitos seculares y propiamente religiosos en su rituali- 
dad. Ello se explica por la conjunción de lo ritual y lo corporativo en sus prácticas religiosas.

- La ritualidad económica, si bien no es hegemónica en el culto, sí ocupa un papel relevante en el desarrollo del mismo. Esto se evidencia en la diversidad de prácticas religiosas de móvil económico que se desarrollan a lo largo de su intenso trabajo cultual. Así, momentos ceremoniales como el recojo de ofrendas, las marchas proterreno, los aires libres y, principalmente, la simbólica y eficaz marcha del dólar explican la relevancia que, en una congregación que opta por una vida casi puritana, adquiere el compromiso material tanto en lo ético como en lo ritual.

- Como se sostuvo al inicio, la ritualidad económica del Movimiento Misionero Mundial constituye un sistema de prácticas que reproduce continuamente la naturaleza de esta congregación. Primero, el sistema de creencias de la iglesia se reactualiza en cada experiencia cultual. Segundo, los imperativos éticos rigurosos que mueven a la comunidad religiosa se legitiman en el desprendimiento económico que supone la participación en ritos como las marchas $\mathrm{u}$ ofrendas. Tercero, los aspectos formales de la ejecución ritual describen la estructura social jerárquica que caracteriza a la iglesia tanto a nivel local como transnacional. Finalmente, las muestras sentimentales de entusiasmo y devoción con las que se ejecutan los rituales visibilizan el carácter emotivo que rige la práctica religiosa del Movimiento en general.

- La predisposición a donar que caracteriza a los fieles que participan de la ritualidad económica de esta iglesia se explica por la conjunción y entrecruzamiento de una lógica de legitimación y otra de reciprocidad. En primer término, a través del ritual se recuerda, desde una mirada institucional, el fuerte compromiso que los fieles deben mostrar hacia su congregación por mandato doctrinal. No obstante, y a la vez, el efecto de plausibilidad de esta internalización es significado por dichos fieles no como una acción movida por valores sino como un intercambio simbólico. Los miembros del Movimiento suelen sentir que donan no solo porque deban hacerlo, sino porque, al donar, ellos se benefician.

- Finalmente, resulta difícil determinar si las practicas religiosas analizadas son rituales que, específicamente, tienen un fin económico o, por el contrario, estrategias corporativas que, en la acción misma, se ritualizan por su forma. Sin embargo, la evidencia etnográfica presentada sugiere que dicha tarea aclaratoria sería imposible. Las marchas, las preparaciones de 
aires libres y el recojo de ofrendas son actividades híbridas. Lo propiamente religioso y lo básicamente económico coexisten, se yuxtaponen y se entremezclan. Desde una mirada externa, son procedimientos de recaudación. Desde los ojos de los fieles, son actos de compromiso simbólico e intercambio. Desde las ciencias sociales, son evidencias del hibridismo que caracteriza a la religiosidad de esta parte del mundo, del sur. 


\section{Bibliografía}

Bastian, J. (1997). La mutación religiosa de América Latina. Para una sociología del cambio social en la modernidad periférica. México D. F.: Fondo de Cultura Económica.

Bastian, J. (1994). Protestantismos y modernidad latinoamericana: historia de unas minorías religiosas activas en América Latina. México D. F.: Fondo de Cultura Económica.

Beck, U. (2003). El dios personal: la individualización de la religión y el espíritu del cosmopolitismo. Barcelona: Paidós

Berger, P. (1972). El dosel sagrado: para una teoría sociológica de la religión. Buenos Aires: Amorrortu Editores.

Bourdieu, P. (2009). Génesis y estructura del campo religioso. En La eficacia simbólica. Religión y política (pp. 43-89). Buenos Aires: Editorial Biblos.

Compañía Peruana de Estudios de Mercados y Opinión Pública (CPI). (2014). Estudio de opinión pública sobre religión - Perú urbano. Recuperado de: https://cpi.pe/images/ upload/paginaweb/archivo/23/OPNAC201407_01.pdf.

Durkheim, E. (1968). Las formas elementales de la vida religiosa. Buenos Aires: Editorial Schapire.

García Canclini, N. (2001). Culturas híbridas: estrategias para entrar y salir de la modernidad. Buenos Aires: Paidós.

Geertz, C. (1988). La religión como sistema cultural. En La interpretación de las culturas (pp. 87-117). Barcelona: Gedisa.

Guber, R. (2011). La etnografía: método, campo y reflexividad. Buenos Aires: Editorial Norma.

Gutiérrez, T. (2017). Protestantismo y política en América Latina. Una interpretación desde las ideologías políticas (tesis de doctorado). Universidad Nacional Mayor de San Marcos, Lima, Perú.

Instituto Nacional de Estadística e Informática (INEI). (2007). Censo de Población y Vivienda 2007. Recuperado de: http://censos.inei.gob.pe/cpv2007/tabulados/\#.

Luckmann, T. (1973). La religión invisible: el problema de la religión en la sociedad moderna. Salamanca: Editorial Sígueme.

Marzal, M. (2002). Tierra encantada: tratado de antropología religiosa de América Latina. Madrid: Trotta

Marzal, M. (2000). Categorías y números en la religión del Perú hoy. En M. Marzal, C. Romero, y J. Sánchez (Eds.). La religión en el Perú al filo del milenio (pp. 21-55). Lima: Fondo Editorial de la Ponticia Universidad Católica del Perú. 
Marzal, M. (1988). Los caminos religiosos de los inmigrantes en la gran Lima. Lima: Fondo Editorial de la Ponticia Universidad Católica del Perú.

Ministerio de Justicia (2017). Registro Nacional de Entidades $y$ Confesiones Religiosas. Recuperado de: https://www.minjus.gob.pe/ registro-nacional-de-confesiones-y-entidades-religiosas/.

Ortiz, L. M. (1980). Instrucciones biblicas para los recién convertidos. Lima: Ediciones Altamira.

Pontificia Universidad Católica del Perú (2017). Religiones y religiosidad en el Perú de hoy. Boletín , 148, del Instituto de Opinión Publica de la PUCP. Recuperado de: http://repositorio.pucp.edu.pe/index/bitstream/handle/123456789/110981/ IOP_0717_01_R5.pdf?sequence=1\&isAllowed=y.

Rappaport, R. (2001). Ritual y religión en la formación de la humanidad. Madrid: Cambridge University Press.

Rolleri, J. (2017a). Entre Cristo y el mundo: ritualidad y pentecostalismo. Una aproximación etnográfica a las prácticas rituales del "Movimiento Misionero Mundial" en el templo central del presbiterio $N .^{\circ} 7$ en Pueblo Libre (tesis de maestría). Lima: Universidad Nacional Mayor de San Marcos.

Rolleri, J. (2017b). La marcha del dólar: pentecostalismo y ritualidad socioeconómica. Una mirada etnográfica a la Iglesia Cristiana Pentecostés "Movimiento Misionero Mundial" en el templo central de Pueblo Libre. Revista Peruana de Antropología, 2(3), pp. 122-139.

Turner, V. (1988). El proceso ritual: estructura y antiestructura. Madrid: Ediciones Taurus.

Weber, M. (1978). Contribución a la sociología de las religiones mundiales. Sociología de la religión (pp. 5-56). Buenos Aires: Editorial La Pléyade. 